\title{
Inhalation of foreign body: "Avoidable lobectomy. A case report"
}

\section{Mbonicura $\mathrm{JC}^{\star 1}$, Bivahagumye $\mathrm{L}^{2}$, Niyonkuru $\mathrm{S}^{3}$, Dunduri $\mathrm{D}^{4}$, Harakandi $\mathrm{S}^{5}$, Ndikumwenayo $\mathrm{F}^{6}$}

\author{
${ }^{1}$ University of Burundi, Teaching Hospital of Kamenge, General Surgery \\ ${ }^{2}$ University of Burundi, Teaching Hospital of Kamenge, ENT \\ ${ }^{3}$ Kira Hospital, General Surgery \\ ${ }^{4}$ University of Burundi, Teaching Hospital of Kamenge, General Surgery \\ ${ }^{5}$ University of Burundi, Teaching Hospital of Kamenge, Anesthesiology \\ ${ }^{6}$ University of Burundi, Teaching Hospital of Kamenge, Pneumology
}

(Dhttps://doi.org/10.15520/jcmro.v3i03.263

Accepted 09-03-2020; Received 04-02-2020; Publish Online 10-03-2020

\author{
Reviewed By: \\ Dr. Negussie Boti \\ Department: \\ Reviewer/CMRO
}

\begin{abstract}
Aim: Describe the difficulties of treating an inhaled foreign body in a resource-limited country.

It was a 6-year-old girl who was brought to an ENT specialist for persistent cough for 2 months after the notion of foreign body inhalation. We report the therapeutic circuit that led to a lobectomy after endoscopic failures.
\end{abstract}

Key words: Inhaled Foreign Body-Lobectomy-Teaching Hospital of Kamenge

\section{INTRODUCTION:}

Bronchopulmonary foreign bodies are common in children and are generally secondary to accidental inhalation. Inhalation of an intra-bronchial foreign body remains a serious accident, especially in young children. Some neglected or unknown foreign bodies destroy the pulmonary territories concerned by air isolation and by accumulation of secretions $[1,2]$ In these situations, surgery becomes inevitable $[1,3,4]$

\section{OBSERVATION:}

This is a 6-year-old girl, who was brought to ENT consultation for persistent cough for 2 months after the notion of foreign body inhalation, the inhalation process having gone unnoticed. Clinically, auscultation was normal, no fever at the first consultation. A radiological-based morphological assessment shows a radiopaque Foreign Body (FB) as shown inFigure 1

The child was hospitalized and a first attempt at extraction with a bronchoscope was unsuccessful. The child was kept in the hospital to try the same maneuver three days

\footnotetext{
* Corresponding author.
}

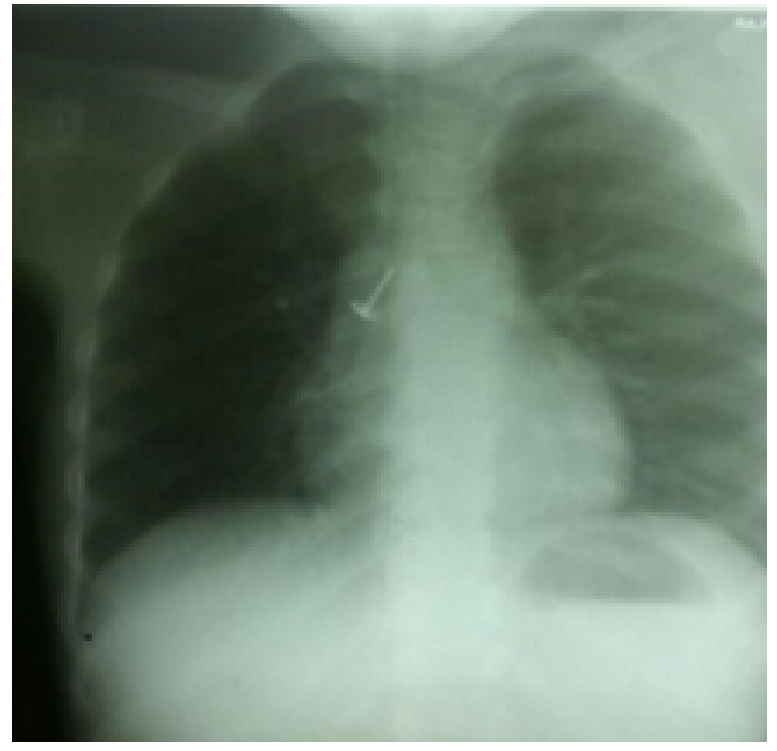

Figure 1. Foreignbody in the right Bronchus

later but it failed again. Note that the child has been on antibiotic therapy since hospitalization. At two weeks of hospitalization, she developed a fever at $40^{\circ} \mathrm{C}$ with chills, a leukocytosis with 21,900 white blood cells and a negative 


\section{Inhalation of foreign body:}

"Avoidable lobectomy. A case report"

malaria test. An aminoglycoside was added to the treatment. At the 3rd week, she continued to develop a fever to which was added a cough and chest pain. The control radiographs note a very low pin with atelectasis Figures 2 and 3
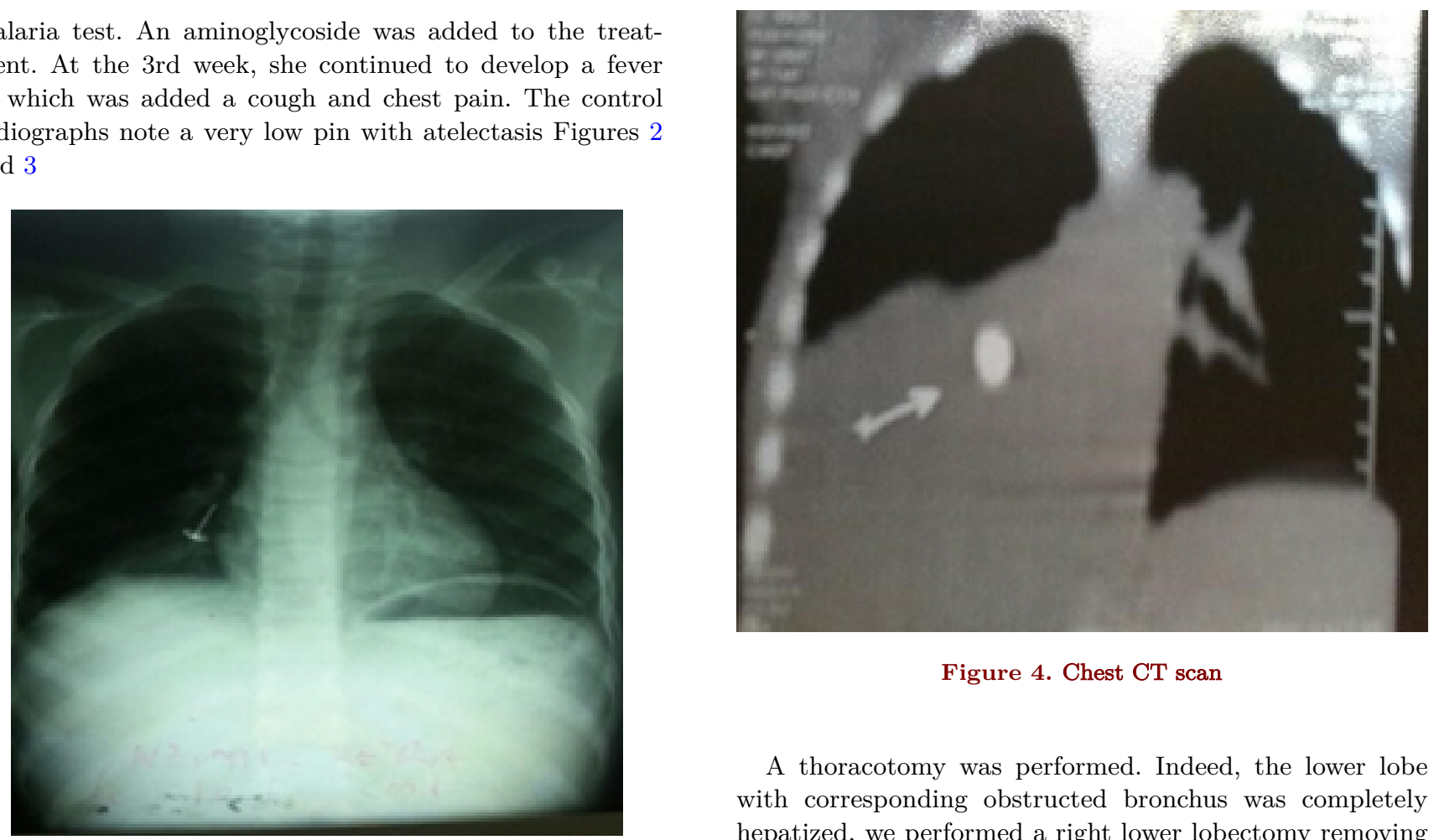

Figure 4. Chest CT scan

Figure 2. Foreignbody in the right inferior secondary bronchi with pulmonary emphysema

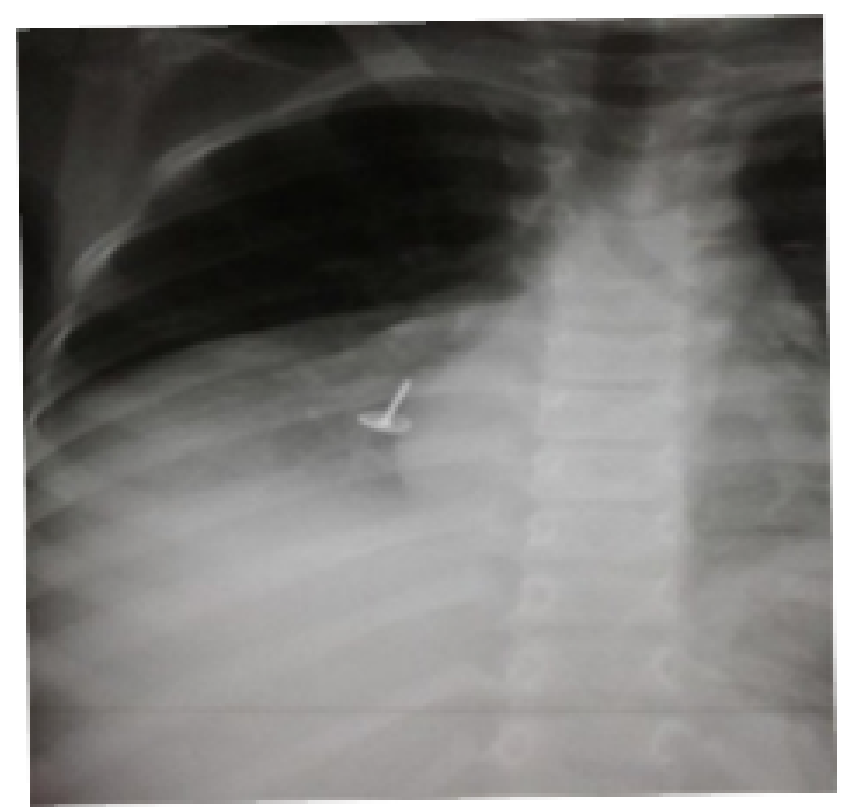

Figure 3. Foreignbody in the right inferior secondary bronchi with atelectasis of the inferiorlobe

The pulmonary auscultation noted a reduced vesicular murmur and crackling sounds. A chest CT scan was requested to better locate the foreign body and diagnose associated parenchymal lesions before extraction surgeryFigure 4

A thoracotomy was performed. Indeed, the lower lobe with corresponding obstructed bronchus was completely hepatized, we performed a right lower lobectomy removing the foreign body at the same time Figure 5

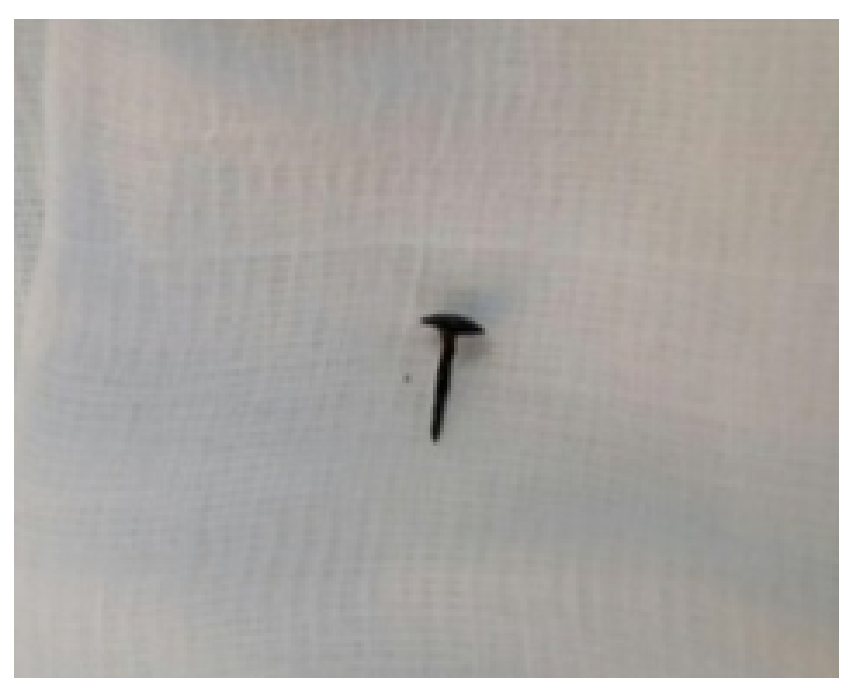

Figure 5. Foreign body

The post-operative events were simple, marked by an apyretic patient on D2PO. The thoracic drain was removed on D3PO. Respiratory physiotherapy started just after the removal of the drain and we authorized the patient to go home at D9PO with a marked respiratory improvementFigure 6

\section{DISCUSSION}

The bronchopulmonary foreign bodies mainly concern young boys, with a tendency to discover objects by placing 


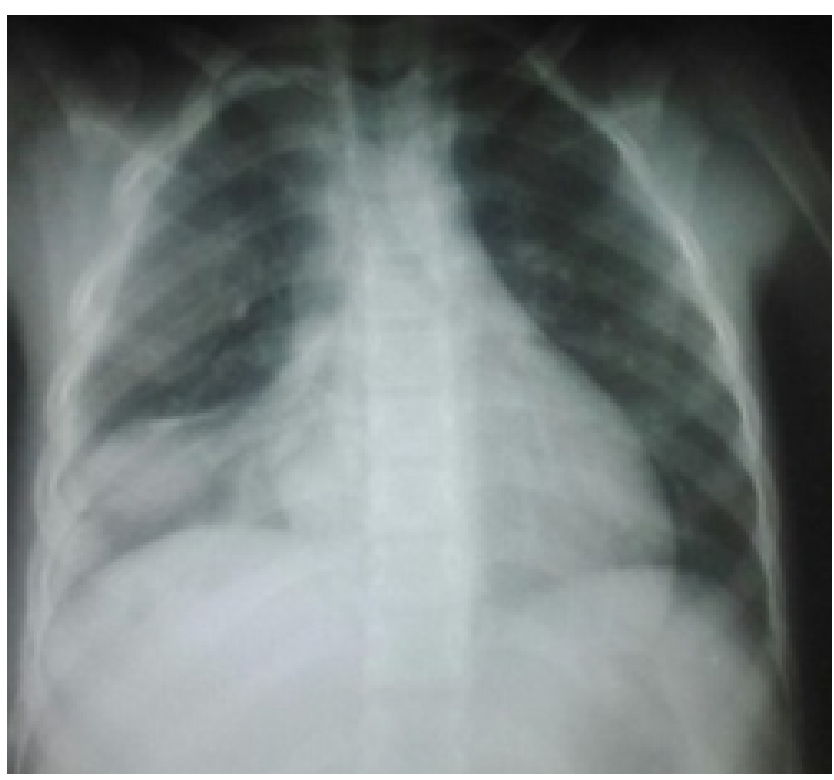

Figure 6. D8PO, drain removed, pulmonary expansion noticed

them in the mouth, but girls are also concerned, in particular veiled girls [3-7]. The nature of the inhaled foreign body varies greatly depending on the socio-cultural and regional conditions, the eating and educational habits of the populations as well as the religious context. They can be organic or inorganic [8-10] These foreign bodies are usually located on the right side in $52.8 \%$ of cases. However, left side or bilateral localization is possible $[11,12]$.In the event of acute respiratory distress in children, it is necessary to systematically think of a bronchopulmonary foreign body. However, inhalation may go unnoticed or the signs may be atypical and thus discover the foreign body at the stage of bronchopulmonary complications $[10,12,13]$.The radiological assessment (standard radiography and chest scanner) is sufficient for the positive diagnosis, localization and extent of destructive parenchymal lesions if the body is radiopaque. If the foreign body is not radiopaque, some indirect signs such as atelectasis or obstructive emphysema should alert the clinician $[7,14]$. A bronchial endoscopy can be used for diagnostic and / or therapeutic purposes. It confirms the presence of a foreign body in the bronchus and specifies the evolutionary stage [10] .Any foreign body having penetrated by the natural ways can be extracted by the same ways provided that it has not migrated through the perforated wall of these ways $[5,6,13]$. There should be no delay in endoscopic extraction [7-15] . Surgery is reserved for endoscopic extraction failures. The reasons for endoscopic failure noted in the literature are: unsuitable instruments, distal migration of the foreign body, hemorrhagic granuloma and foreign body not visualized [9] Other indications for surgery include sharp and pointed foreign bodies with risk of migration and damage to surrounding structures, old foreign bodies with irreversible respiratory damage [9-11] In our case, the surgery was motivated both by the failure of endoscopic extraction and by how long the foreign body was in place. This surgery was preceded by a chest CT scan to better ensure the final seat of the foreign body and secondary bronchopulmonary destruction, which allowed us to consider the actions to be taken. Other authors also suggest that the intervention be immediately preceded by the thoracic scanner to properly locate the foreign body due to its mobility $[7,9,11,15]$. Irreversible parenchymal damage requires sometimes extensive excision [15] . An early extraction period limited to the first 72 hours after inhalation of foreign bodies is an important condition for an uncomplicated course $[11,13]$. Since bronchopulmonary foreign body surgery must be conservative, it is limited as much as possible to bronchotomy or extraction pneumotomy after detection and manual blocking of the foreign body in order to avoid its migration $[9,10]$. But, faced with a situation of irreversible parenchymal destruction, pulmonary resection procedures must be performed and depend on the extent of these lesions [9, 10] In our situation, this surgery was made difficult especially by the absence of selective intubation in anesthetic practice.The post-operative events are mostly simple. Operative mortality varies between 0.05 and $0.5 \%$ in the literature $[9,10]$. Morbidity is dominated by heart rhythm disturbances, bronchial fistula, pulmonary edema and post-pneumonectomy syndrome $[10,11]$

\section{CONCLUSION:}

Broncho-pulmonary foreign bodies are observed especially in young children. In the context of countries with limited resources, due to the lack of appropriate early management either due to lack of diagnostic knowledge or due to the lack of suitable bronchoscopy instruments, surgery becomes an alternative for treatment, in particular after endoscopic failure or in case of irreversible respiratory sequelae. Surgery should be conservative and parenchymal resections limited. Preventive measures occupy the golden place, especially in children.

\section{REFERENCES}

[1] Zineddine A, Gueddari W, Abid A. Corps étrangers trachéo-bronchiques chez l'enfant. Archives de Pédiatrie. 2009;16(6):959-961. Available from: https://dx.doi.org/10. 1016/s0929-693x(09)74218-6.

[2] Nzomvuama A, Nsiala J, Kayembe JM. Pneumonectomie pour corps étranger intrabronchique. Indication justifiée ou rançon de la pauvreté ? A propos d'un cas. Chirurgie Thoracique et Cardio-vasculaire. 2016;20(1):52-54.

[3] Kiss L, Lapadatu E, Balin I. The incidence of emergency thoracotomy in thoracic trauma. Chest. 1997;92(4):269-75.

[4] Lawson S. Les corps étrangers en ORL au CHU de Kara. Med Afr Noire. 2010;57:461-465.

[5] Mnejja M. Bronchoscopie pour inhalation de corps étrangers chez l'enfant : à propos de 223 cas. Archives de Pédiatrie. 2000;19:670-674.

[6] Brouchet L, Marcheix B, Renaud C, Berjaud J, Dahan M; 2005.

[7] Morad S, Benjelloun H, Zaghba N, Bakhatar A, Yassine N, Bahlaoui A. Inhalation accidentelle d'épingle à foulard : à propos de 39 observations. Revue des Maladies Respiratoires. 2015;32:A146-A146. Available from: https://dx.doi. 
org/10.1016/j.rmr.2014.10.091.

[8] Benjelloun $\mathrm{H}$, Zaghba N. Les corps étrangers trachéobronchiques chez l'adulte. Pan Afr Med J. 2014;19:220-220.

[9] Caidi M, Kabiri H, Lazrek I, Maslout AE, Osman AB. Chirurgie des corps étrangers intrabronchiques. Annales de Chirurgie. 2002;127(6):456-460. Available from: https: //dx.doi.org/10.1016/s0003-3944(02)00795-2.

[10] Diarra O, Diatta S. Chirurgie des corps étrangers intrabronchiques à Dakar : à propos de 13 cas. Ann Afr Chir Thor Cardiovasc. 2012;7(2).

[11] Nambirajan L. Bhatnagar V Pericardial foreign body. J Pediatrsurg. 2001;36:936-944.

[12] Hebbazi A, Khattabi WE, Bopaka R, Jabri H, Afif H. L'inhalation d'épingle à foulard: urgence pneumologique émergente. Pan African Medical Journal. 2015;22:277-277. Available from: https://dx.doi.org/10.11604/pamj.2015.22. 277.6928.

[13] Arsalane A, Zidane A, Atoini F, Traibi A, Kabiri EH. Deux cas d'extraction chirurgicale de corps étrangers après inhalation d'épingle de foulard. Revue de Pneumologie Clinique. 2009;65(5):293-296. Available from: https://dx.doi.org/10. 1016/j.pneumo.2009.02.004.

[14] Rabiou S, Ouadnouni Y. Corps étranger intra-thoracique méconu : cause inhabituelle de douleur thoracique chronique chez l'adulte. Cas clinique. Chirurgie Thoracique et cardiovasculaire;2015(4):239-240.

[15] Kendja F, Ouede R, Ehounoud H, Demine B, Yaho P, Tanauh Y. Poumons détruits de l'enfant sur corps étrangers : indications et résultats. Chirurgie Thoracique Cardiovasculaire. 2013;17(2):108-111. 